\title{
Influence of morphometry and biomechanics on diet selection in three portunid crabs
}

\author{
Juan Freire*, M. Paz Sampedro, Eduardo González-Gurriarán \\ Departamento de Bioloxía Animal, Bioloxía Vexetal e Ecoloxía, Universidade da Coruña, Campus da Zapateira s/n, \\ E-15071 A Coruña, Spain
}

\begin{abstract}
Morphometric and biomechanical characteristics [size, mechanical advantages (MAs), muscle mass ratio (MR)] of the chelipeds of Necora puber, Liocarcinus depurator and Liocarcinus arcuatus (Crustacea, Decapoda, Portunidae) were analyzed to investigate their relation to diet selection patterns observed from gut content analysis of crabs from the Ría de Arousa (Galicia, NW Spain). The size of the chelipeds relative to body size is similar in the 3 species, but there are important differences in biomechanical parameters. Both males and females demonstrate an interspecific morphometric gradient where there is an inverse relationship between MA and MR of the chelipeds. The prey consumed by portunids in the Ria de Arousa was classified according to its mobility and presence of a hard exoskeleton. The diet of $L$. depurator had a high morphological diversity as the functional structure of the chelipeds is more versatile than in the other species. Chelipeds of $L$. depurator are highly mobile because the MAs are relatively low, but the decrease in force produced is compensated by a relative increase in muscle mass. L. arcuatus has a lower $M R$ but the highest $M A$, hence the force produced depends more on the design of the chelipeds. These characteristics give rise to appendages with little mobility, which is reflected in a diet made up mainly of sedentary prey without an exoskeleton. $N$ puber has intermediate trophic and biomechanical characteristics; its prey are primarily mobile and have hard exoskeletons. Ontogenetic changes are the main factor reponsible for life history variation in the diet, and they are related to biomechanical factors due to the absolute growth of the chelipeds. Growth gives access to prey with hard exoskeletons, especially in the case of $L$. depurator, whereas the changes in relative growth are associated with the onset of sexual maturity and reproductive behavlour. Within a species, the morphometric patterns observed may be attributed to non-trophic selection processes, and they have no major influence on the diet, which is conditioned mainly by the absolute growth of the chelipeds and muscle mass. On a longer evolutionary scale, the interspecific diversity in feeding habits and morphometry are correlated, although the causal mechanism could not be determined
\end{abstract}

KEY WORDS: Biomechanics Diet selection - Feeding - Morphometry - Decapoda Portunidae

\section{INTRODUCTION}

Decapod crustaceans are the dominant epibenthic invertebrates in the Ría de Arousa (Galicia, NW Spain), especially in the extensive soft-bottom areas devoted to the raft culture of mussel Mytilus galloprovincialis (Tenore et al. 1982). The density and biomass of decapods are higher in the Ría de Arousa than in other rías, and in raft areas compared to zones that are not used for mussel culture (González-Gurriarán 1982, Romero et al. 1982). In particular, food provided by mussels and

·E-mail: jfreire@udc.es the associated epifauna on rafts have determined the changes in the abundance and distribution patterns observed for the epibenthic decapods in the Ría de Arousa (González-Gurriarán et al. 1989, Freire et al. 1990, Freire 1993, in press, Freire \& GonzálezGurriarán 1995). Portunids (Necora puber, Llocarcinus depurator and Liocarcinus arcuatus) are the most abundant decapods in the Ría de Arousa, and their population dynamics are linked to new habitats created by mussel culture (González-Gurriarán 1985, Fernández et al. 1991, Freire et al. 19911.

There are major differences in the size and morphology of chelipeds in brachyuran crustaceans, as well as in the degree of sexual dimorphism and heterochely 
(Schäfer 1954, Hartnoll 1974, 1978, Vermeij 1977) In the portunids the morphological structure of chelae has been analyzed because of their importance in predation techniques and prey selection mechanisms (Elner 1980, Hughes \& Seed 1981, Blundon \& Kennedy 1982, ap Rheinallt \& Hughes 1985, ap Rheinallt 1986). Chelipeds are relatively simple lever systems in which the mobility and the force produced are inversely related. They generate forces that are applied by means of occlusive surfaces, facilitating the handling of resistant prey with hard exoskeletons or a shell (Warner \& Jones 1976).

This study examines morphometrical and biomechanical aspects of the chelipeds of Necora puber, Liocarcinus depurator and Liocarcinus arcuatus in order to test the hypothesis that these characteristics cause differences in diet selection, both interspecifically and between life history stages within species.

\section{MATERIALS AND METHODS}

Diei composition. A detailed description of the sampling areas, methodology and diet composition and its spatial and seasonal changes and variability related to life history is given elsewhere (Freire 1993, in press, Freire \& González-Gurriarán 1995), and only a brief summary is presented here. Diet composition was examined in approximately 10000 gut contents of Necora puber, Liocarcinus depurator and Liocarcinus arcuatus. Specimens were caught monthly from July 1989 to June 1990 in different sampling stations located in 3 types of soft-bottom habitat: mussel culture areas inhabited by the 3 species, the central channel of the ría where only $L$. depurator was present, and a beach area where only $L$. arcuatus was present $(N$. puber is a species typical of subtidal rocky areas, inhabiting only soft bottoms in mussel culture areas, González-Gurriarán 1985). The prey consumed by portunids in the Ría de Arousa was classified according to the following characteristics: mobility (sessile or slow moving and mobile) and presence or absence of a hard exoskeleton (non-articulated or articulated as in ophiuroids, where the handling and ingestion of the prey is carried out by crushing the articulated areas and not the exoskeleton itself) (Lawton \& Elner 1984).

Morphometry and biomechanics. Morphometrics were studied in specimens fixed in $4 \%$ formaldehyde for 24 to $48 \mathrm{~h}$ and preserved in $70 \%$ alcohol. Males and females in intermoult stage with body sizes (carapace width between the tips of the fifth anterolateral spines, CW) covering the typical range for each species and sex (Necora puber. 20 to $80 \mathrm{~mm}$, Liocarcinus depurator: 10 to $60 \mathrm{~mm}$, L. arcuatus: 10 to $40 \mathrm{~mm}$ ) were selected. The specimens used did not show any signs of regeneration or malformation of the chelae and presented the typical heterochely of the species studied (with a right crusher chela and a left pincer chela). The heterochely of portunids is defined by the different morphology of the dentition in both chelipeds, although their sizes are similar. The crusher chela, usually the right one, is larger and has blunt molar shaped teeth, with an ample contact surface and a greater sized molar process at the base of the dactylus. The pincer chela has sharp teeth with triangular sections.

The following variables were measured (to the nearest $0.1 \mathrm{~mm}$ ) for each specimen using a digital caliper (Fig 1): CW; length, width and height (excluding the spine located in the dactylus insertion in the case of Nccora puber and Liocarcinus depuratorl of the propodius of both chelipeds. The following data were recorded for the study of the mechanical advantages (MAs) in chelipeds (Warner \& Jones 1976): $\mathrm{L}_{1}$, distance between the pivot (point of articulation between the dactylus and propodius! and the point of insertion on the dactylus of the closer apodeme muscle; $\mathrm{L}_{2 a}$, dactylus length (distance between the pivot and the tip of the dactylus); $\mathrm{L}_{2 b}$ (only in the crusher chela), distance between the pivot and the molar process at the base of the dactylus. The apodeme of the closer muscle, muscle and tegument from the propodius and dactylus were separated and the dry weight was obtained for each component after $48 \mathrm{~h}$ at $70^{\circ} \mathrm{C}$. The proportion of the weight of the cheliped which is made up of muscle was estimated: muscle mass ratio $(\mathrm{MR})=$ muscle dry weight/(muscle dry weight + tegument dry weight). Due to the small size of some individuals, the apodemes could not be completely removed to obtain their dry weight; for this reason these variables were not included in the multivariate analyses.

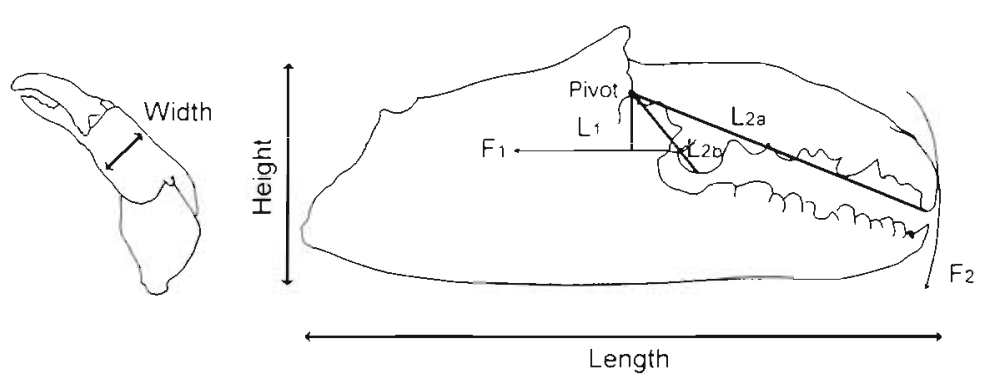

Fig. 1. Diagram of a crusher cheliped showing the morphometric variables measured (length, height and width of the propodius), location of pivot (point of articulation between dactylus and propodius), parameters of the ideal mechanical advantages $\left(\mathrm{L}_{1}, \mathrm{~L}_{2 s}\right.$ and $\left.\mathrm{L}_{2 b}\right)$ and directions through which the force applied $F_{1}$ and the force produced $F_{2}$ act. In a system with frictionless pivots: $F_{1} \times L_{1}=F_{2} \times L_{2}$ or $F_{2} / F_{1}=L_{1} / L_{2}=$ mechanical advantage 
A series of ideal MAs were estimated, defined by the ratio of the lever lengths: $M A_{a}=L_{1} / L_{2 a}$, and $M A_{b}=$ $\mathrm{L}_{1} / \mathrm{L}_{2 b}$ (only in the right chela). Moreover, the estimate of the functional MA is based on the direct measurement of the force applied $\left(F_{1}\right)$ and the force produced $\left(F_{2}\right)\left(\mathrm{MA}=\mathrm{F}_{2} / \mathrm{F}_{1}\right)$. In a system with frictionless pivots: $F_{1} \times L_{1}=F_{2} \times L_{2}$ or $F_{2} / F_{1}=L_{1} / L_{2} ;$ which means that the force produced by the system increases with the ideal MA $\left(\mathrm{L}_{1} / \mathrm{L}_{2}\right)$. However the speed of the resultant movement and the distance moved both decrease in proportion (Warner \& Jones 1976). $\mathrm{L}_{2}$ depends on the position along the axis of the dactylus, which is why maximum $\left(L_{2 a}\right)$ and minimum $\left(L_{2 b}\right)$ levers have been defined.

The MAs and MR of each cheliped were compared between sexes for each species and between species for each sex using analysis of variance (ANOVA) followed by pairwise comparisons using HSD-Tukey tests. In order to analyze the ontogenetic changes in the morphometrical and biomechanical characteristics of chelipeds, the linear correlation of CW with MAs and MRs for each sex and species was obtained, and a series of allometric equations which relate $\mathrm{CW}$ to the different variables obtained to determine the mechanical advantages and dry weights of the muscle, tegument and apodeme for both chelipeds $\left(y=a C W^{b}\right)$ were fitted using minimum square linear regression after $\log _{10}$-transformation. The parameters for the equations obtained for each sex and species were compared between sexes within each species and between species for each sex using analysis of covariance (ANCOVA). In comparisons between species, multiple pairwise comparisons were carried out when differences were found between slopes $(p<0.05)$, applying the Bonferroni correction to maintain a probability level of $p=0.05$. For the description of the patterns of interspecific morphometrical variability, principal component analyses for each sex were carried out on the correlation matrix of the log-transformed variables ( $\mathrm{CW}$, length, width, height, MAs and MRs of both chelipeds).
Table 1. Mean (SD) of mechanical advantages (MA) and muscle mass ratio (MR) of chelipeds for males and females of 3 species. F-statistics (significance level) of ANOVA carried out to compare these parameters between sexes for each species are shown ( $n=$ sample size). See 'Materials and methods' for equation used to derive MA and MR

\begin{tabular}{|c|c|c|c|}
\hline & Males & Females & $F(\mathrm{p})$ \\
\hline \multicolumn{4}{|c|}{ Necora puber } \\
\hline \multicolumn{4}{|c|}{ Crusher cheliped $n=45$} \\
\hline $\mathrm{MA}_{\mathrm{c}}$ & $0.294(0.030)$ & $0.275(0.015)$ & $11.10(0.001)$ \\
\hline$M A_{b}$ & $0.843(0.079)$ & $0.845(0.049)$ & $0.03(0.865)$ \\
\hline $\mathrm{MR}$ & $0.206(0.054)$ & $0.201(0.048)$ & $0.21(0.645)$ \\
\hline \multicolumn{4}{|c|}{ Pincer cheliped } \\
\hline$M A_{i t}$ & $0.254(0.046)$ & $0.246(0.018)$ & $0.28(0.598)$ \\
\hline $\mathrm{MR}$ & $0.218(0.100)$ & $0.189(0.089)$ & $1.68(0.199)$ \\
\hline \multicolumn{4}{|c|}{ Liocarcinus depurator } \\
\hline \multicolumn{4}{|c|}{ Crusher cheliped $n=89$} \\
\hline$M A_{d}$ & $0.271(0.020)$ & $0.276(0.032)$ & $0.51(0.478)$ \\
\hline $\mathrm{MA}_{b}$ & $0.782(0.066)$ & $0.791(0.061)$ & $0.28(0.597)$ \\
\hline$M R$ & $0.231(0.039)$ & $0.227(0.037)$ & $0.16(0.694)$ \\
\hline \multicolumn{4}{|c|}{ Pincer cheliped } \\
\hline $\mathrm{MA}_{d}$ & $0.225(0.020)$ & $0.233(0.019)$ & $2.54(0.114)$ \\
\hline MR & $0.233(0.048)$ & $0.225(0.043)$ & $0.35(0.556)$ \\
\hline \multicolumn{4}{|c|}{ Liocarcinus arcuatus } \\
\hline \multicolumn{4}{|c|}{ Crusher cheliped $n=62$} \\
\hline$M A_{d}$ & $0.310(0.022)$ & $0.288(0.027)$ & $17.28(0.000)$ \\
\hline $\mathrm{MA}_{\mathrm{b}}$ & $0.865(0.094)$ & $0.824(0.068)$ & $6.85(0.010)$ \\
\hline $\mathrm{MR}$ & $0.191(0.064)$ & $0.201(0.058)$ & $0.61(0.437)$ \\
\hline \multicolumn{4}{|c|}{ Puncer cheliped } \\
\hline $\mathrm{MA}_{\mathrm{c}}$ & $0.261(0.037)$ & $0.259(0.027)$ & $0.00(0.954)$ \\
\hline$M R$ & $0.189(0.116)$ & $0.190(0.067)$ & $0.02(0.900)$ \\
\hline
\end{tabular}

the right cheliped were larger in males. The interspecific differences of the MAs and MRs were sex-dependent (Table 2). In males all the MAs for both chelipeds were lowest in $L$. depurator $(p<0.001)$; however, only $\mathrm{MA}_{\mathrm{a}}$ of the crusher cheliped was significantly higher in $L$. arcuatus than in $N$. puber In contrast, the differences were not as important in females and only $\mathrm{MA}_{\mathrm{b}}$

\section{RESULTS}

\section{Morphometry and biomechanics}

The mean MAs and MRs of chelipeds for each species and sex are shown in Table 1 . No significant differences were found between males and females for Liocarcinus depurator, while for Necora puber only the $\mathrm{MA}_{\mathrm{a}}$ of the crusher cheliped was significantly larger in males than in females. For Llocarcinus arcuatus there were no significant differences in the MRs between sexes, however both MAs of
Table 2. F-statistic (significance level) of ANOVA carried out to compare the mechanical advantages (MA) and muscle ratio (MR) of chelipeds between species for males and females. In cases where $p<0.05$, pairwise comparisons were made using the HSD-Tukey test (underlined species were not significantly different, $p>0.05$ ). NPU: Necora puber; LDE: Liocarcinus depurator, LAR: L. arcuatus

\begin{tabular}{|c|c|c|c|c|}
\hline & $F(\mathrm{p})$ & $\begin{array}{l}\text { Males - } \\
\text { HSD-Tukey test }\end{array}$ & $F(p)$ & $\begin{array}{l}\text { Cemales - } \\
\text { HSD-Tukey test }\end{array}$ \\
\hline \multicolumn{5}{|c|}{ Crusher cheliped } \\
\hline $\mathrm{MA}_{\mathrm{d}}$ & $51.08(0.000)$ & LDE NPU LAR & $3.49(0.034)$ & NPU LDE LAR \\
\hline $\mathrm{MA}_{\mathrm{b}}$ & $20.72(0.000)$ & LDE NPU LAR & $4.75(0.011)$ & LDE LAR NPU \\
\hline$M R$ & $11.45(0.000)$ & LAR NPU LDE & $1.94(0.149)$ & \\
\hline \multicolumn{5}{|c|}{ Pincer cheliped } \\
\hline$M A_{d}$ & $24.21(0.000)$ & LDE NPU LAR & $0.62(0.503)$ & \\
\hline $\mathrm{MR}$ & $4.72(0.010)$ & LDE NPU LAR & $1.75(0.179)$ & \\
\hline
\end{tabular}


showed significant differences between species. The MR of chelipeds was similar in males and females of each species (Table 1). There were no interspecific differences for females, but in the case of males both appendages presented greater MRs in $L$. depurator than in $N$. puber and reached minimum values for $L$. arcuatus (Table 2).

The MAs and MRs for Necora puber were independent of body size, except in the case of $\mathrm{MA}_{\mathrm{a}}$ of the crusher cheliped in males, which presented a significant positive correlation with CW (Table 3). As Liocarcinus depurator grew in size MAs decreased significantly (except $\mathrm{MA}_{a}$ of the crusher cheliped in females) in both chelae. L. arcuatus had a different pattern of ontogenetic variability in that the correlations observed between $M R$ and $C W$ were higher than the correlations between MAs and CW. All the MAs in females of this species decreased with growth, whereas in maies there were oniy significant correlations in the case of the right chela (negative for $\mathrm{MA}_{\mathrm{b}}$ and positive for $\mathrm{MA}_{a}$ ). The MRs had a high negative correlation with body size, which implies that the cheliped grows more in size than in muscle mass.

Ontogenetic changes in the morphology of the appendages and the relationship between mechanical parameters and body size were analyzed fitting allometric equations for the variables used to calculate MAs and MR (Table 4). The levers of chelipeds, and the apodeme, muscle and tegument dry weights showed high coefficients of determination $\left(\mathrm{r}^{2}>0.8, \mathrm{p}<\right.$ 0.01 , with the exception of the apodemes of Liocarcinus arcuatus females due to the small sample size). There were major sexual differences in the relative growth of the chelipeds, and especially of the levers used in the estimation of the MAs (Table 5), which points to a divergence between males and females in biomechanical characteristics with growth. With reference to the crusher cheliped in males, the allometry of $L$. arcuatus was greater than in the other species for all the variables, while the differences between $L$. depu- rator and Necora puber were restricted to $\mathrm{L}_{2 a}$ (Table 6). In females, on the other hand, the slopes of the equations corresponding to $N$. puber were higher in all cases than for $L$. arcuatus; however $L$. depurator had a greater variability, due in part to the smaller number of specimens analyzed. Interspecific differences for the left cheliped were not significant, except in the case of $\mathrm{L}_{1}$, which has a relative growth characterized by a larger slope in $L$. arcuatus. The differences in the allometry coefficient of the different levers $\left(\mathrm{L}_{1}, \mathrm{~L}_{2 \mathrm{a}}\right.$ and $\left.\mathrm{L}_{2 \mathrm{~b}}\right)$ for each species and sex were generally more important for the species of the genus Liocarcinus, which resulted in higher correlations between the MAs of the chelipeds and body size than in the case of $N$. puber.

In males the slope of the equation for muscle dry weight in both chelipeds was greater for Liocarcinus depurator and similar in Necora puber and L. arcuatus (although significant differences did exist in the case of the right chela) (Table 5). In contrast, the allometry of tegument dry weight was greater in L. arcuatus $(\mathrm{b}>4)$ than in $L$. depurator and especially in $N$. puber. In females the quantitative importance of the differences between species was smaller, especially in tegument weight; although, as is the case in males, the slope of the relationships corresponding to muscle weight was greater in $L$. depurator. For each species and sex, the allometry coefficients of tegument and muscle dry weights were similar, except in the case of $L$. arcuatus, which showed a negative correlation between MR and body size. The apodeme of the closer muscle had a similar growth pattern in males and females (Table 5). The slopes were higher for the right apodeme than for the left, except for $L$. arcuatus; in general interspecific variability was scarce (Table 6).

The results of the principal component analyses carried out to describe the morphometric variability between species were similar for males and females, in the correlation of the different variables with the axes extracted as well as in the proportion of variance explained (Fig. 2). Axis 1 represented body size, pre-

Table 3. Linear correlation, r (significance level), between carapace width (CW) and mechanical advantages (MA) and between $\mathrm{CW}$ and muscle mass ratio (MR) of chelipeds for males and females of the 3 species studied (analysis based on $\log _{10^{-}}$ transformed data)

\begin{tabular}{|c|c|c|c|c|c|c|}
\hline & \multicolumn{2}{|c|}{ Necora puber } & \multicolumn{2}{|c|}{ Liocarcinus depurator } & \multicolumn{2}{|c|}{ Liocarcinus arcuatus } \\
\hline & Males & Females & Males & Females & Males & Females \\
\hline \multicolumn{7}{|c|}{ Crusher cheliped } \\
\hline $\mathrm{MA}_{\mathrm{a}}$ & $0.332(0.021)$ & $-0.287(0.100)$ & $-0.401(0.000)$ & $0.231(0.357)$ & $0.226(0.078)$ & $-0.470(0.000)$ \\
\hline $\mathrm{MA}_{\mathrm{b}}$ & $-0.087(0.557)$ & $-0.321(0.064)$ & $-0.415(0.000)$ & $-0.486(0.041)$ & $-0.486(0.000)$ & $-0.238(0.096)$ \\
\hline $\mathrm{MR}$ & $-0.205(0.163)$ & $0.007(0.968)$ & $-0.117(0.275)$ & $-0.385(0.115)$ & $-0.758(0.000)$ & $-0.639\{0.000\}$ \\
\hline \multicolumn{7}{|c|}{ Pincer cheliped } \\
\hline$M A_{d}$ & $0.088(0.550)$ & $0.083(0.642)$ & $-0.432(0.000)$ & $-0.568(0.014)$ & $0.167(0.195)$ & $-0.243(0.083)$ \\
\hline$M R$ & $0.064(0.665)$ & $-0.128(0.501)$ & $0.055(0.610)$ & $-0.002(0.993)$ & $-0.562(0.000)$ & $-0.709(0.000)$ \\
\hline
\end{tabular}


Table 4. Parameters of the allometric equations (intercept loga and slope $b$ ) fitted for males and females of each species that relate carapace width and the different variables obtained to determine the mechanical advantages and dry weights (DW) of muscle, tegument and apodeme of the propodius of both chelipeds. The coefficients of determination $\left(\mathrm{r}^{2}\right)$ were significant $(\mathrm{p}<0.01)$ in all except the case of the apodeme of the pincer cheliped of the females of Liocarcinus arcuatus (results not shown). See 'Materials and methods' for definitions of $\mathrm{L}_{1}, \mathrm{~L}_{2 \mathrm{~d}}$ and $\mathrm{L}_{2 b}$

\begin{tabular}{|c|c|c|c|c|c|c|}
\hline & \multicolumn{3}{|c|}{- Males $\longrightarrow$} & \multicolumn{3}{|c|}{ Females } \\
\hline & Intercept (SE) & Slope (SE) & $r^{2}$ & Intercept (SE) & Slope (SE) & $r^{2}$ \\
\hline \multicolumn{7}{|l|}{ Necora puber } \\
\hline \multicolumn{7}{|l|}{ Crusher cheliped } \\
\hline Muscle DW & $-6.20(0.32)$ & $3.15(0.18)$ & 0.86 & $-6.29(0.53)$ & $3.14(0.31)$ & 0.77 \\
\hline Tegument DW & $-5.97(0.16)$ & $3.36(0.09)$ & 0.97 & $-5.79(0.34)$ & $3.21(0.20)$ & 0.90 \\
\hline L & $-1.10(0.07)$ & $1.07(0.04)$ & 0.93 & $-1.09(0.12)$ & $1.04(0.07)$ & 0.87 \\
\hline $\mathrm{L}_{2 \mathrm{a}}$ & $-0.38(0.07)$ & $0.96(0.04)$ & 0.93 & $-0.64\{0.10\}$ & $1.10(0.06)$ & 0.91 \\
\hline & $-1.07(0.08)$ & $1.10(0.05)$ & 0.92 & $-1.15(0.12)$ & $1.12(0.07)$ & 0.89 \\
\hline Apodeme DW & $-7.73(0.55)$ & $3.40(0.32)$ & 0.90 & $-8.03(0.79)$ & $3.55(0.45)$ & 0.91 \\
\hline \multicolumn{7}{|l|}{ Pincer cheliped } \\
\hline Muscle DW & $-6.37(0.33)$ & $3.15(0.19)$ & 0.86 & $-6.13(0.46)$ & $2.98(0.27)$ & 0.82 \\
\hline Tegument DW & $-5.53(0.29)$ & $3.01(0.17)$ & 0.87 & $-5.78(0.14)$ & $3.13(0.08)$ & 0.98 \\
\hline $\mathrm{L}_{1}$ & $-1.05(0.08)$ & $0.99(0.05)$ & 0.90 & $-1.05(0.12)$ & $0.97(0.07)$ & 0.87 \\
\hline $\mathrm{L}_{2 a}$ & $-0.39(0.11)$ & $0.95(0.06)$ & 0.83 & $-0.27(0.34)$ & $0.86(0.20)$ & 0.37 \\
\hline Apodeme DW & $-7.06(0.51)$ & $2.83(0.30)$ & 0.78 & $-5.86(0.72)$ & $2.12(0.42)$ & 0.60 \\
\hline \multicolumn{7}{|c|}{ Liocarcinus depurator } \\
\hline \multicolumn{7}{|c|}{ Crusher cheliped } \\
\hline Muscle DW & $-6.50(0.13)$ & $3.40(0.08)$ & 0.95 & $-5.90(0.44)$ & $3.00(0.28)$ & 0.87 \\
\hline Tequment DW & $-6.10(0.10)$ & $3.48(0.06)$ & 0.98 & $-6.06(0.36)$ & $3.45(0.23)$ & 0.94 \\
\hline $\mathrm{L}_{1}$ & $-1.02(0.04)$ & $1.02(0.03)$ & 0.95 & $-0.99(0.16)$ & $0.98(0.10)$ & 0.86 \\
\hline $\mathrm{L}_{2 a}$ & $-0.58(0.03)$ & $1.10(0.02)$ & 0.98 & $-0.22(0.20)$ & $0.85(0.13)$ & 0.73 \\
\hline $\mathrm{L}_{2 b}$ & $-1.06(0.03)$ & $111(0.02)$ & 0.97 & $-1.19(0.02)$ & $1.18(0.11)$ & 0.89 \\
\hline Apodeme DW & $-7.21(0.37)$ & $3.26\{0.23\}$ & 0.88 & $-8.33(1.13)$ & $3.94(0.71)$ & 0.89 \\
\hline \multicolumn{7}{|l|}{ Pincer cheliped } \\
\hline Muscle DW & $-6.93(0.16)$ & $3.54(0.10)$ & 0.94 & $-6.45(0.45)$ & $3.23(0.29)$ & 0.89 \\
\hline Tegument DW & $-6.35(0.08)$ & $3.50(0.05)$ & 0.98 & $-5.92(0.22)$ & $3.24(0.14)$ & 0.97 \\
\hline $\mathrm{L}_{1}$ & $-1.12(0.04)$ & $1.01(0.03)$ & 0.95 & $-0.74(0.12)$ & $0.77(0.08)$ & 0.86 \\
\hline $\mathrm{L}_{2 \alpha}$ & $-0.64(0.02)$ & $1.12(0.01)$ & 0.99 & $-0.50(0.07)$ & $1.02(0.05)$ & 0.97 \\
\hline Apodeme DW & $-6.85(0.38)$ & $2.85(0.24)$ & 0.80 & $-4.32(0.45)$ & $1.19(0.29)$ & 0.68 \\
\hline \multicolumn{7}{|c|}{ Liocarcinus arcuatus } \\
\hline \multicolumn{7}{|c|}{ Crusher cheliped } \\
\hline Muscle DW & $-6.29(0.18)$ & $3.32(0.12)$ & 0.92 & $-5.62(0.17)$ & $2.73(0.12)$ & 0.91 \\
\hline Tegument DW & $-6.79(0.16)$ & $4.14(0.11)$ & 0.96 & $-5.79(0.13)$ & $3.31(0.10)$ & 0.96 \\
\hline $\mathrm{L}_{1}$ & $-1.27(0.04)$ & $1.23(0.03)$ & 0.97 & $-0.86(0.05)$ & $0.88(0.04)$ & 0.92 \\
\hline $\mathrm{L}_{2 \mathrm{a}}$ & $-0.70(0.02)$ & $1.19(0.02)$ & 0.99 & $-0.48(0.03)$ & $1.00(0.02)$ & 0.98 \\
\hline $\mathrm{L}_{2 \mathrm{~b}}$ & $-1.36(0.06)$ & $1.35(0.04)$ & 0.95 & $-0.86(0.05)$ & $0.95(0.04)$ & 0.94 \\
\hline Apodeme DW & $-6.69(0.48)$ & $3.03(0.33)$ & 0.81 & $-4.54(0.53)$ & $1.34(0.39)$ & 0.50 \\
\hline \multicolumn{7}{|l|}{ Pincer cheliped } \\
\hline Muscle DW & $-6.41(0.19)$ & $3.25(0.14)$ & 0.90 & $-5.56(0.19)$ & $2.57(0.14)$ & 0.88 \\
\hline Tegument DW & $-6.81(0.22)$ & $4.01(0.16)$ & 0.92 & $-5.96(0.15)$ & $3.35(0.11)$ & 0.95 \\
\hline & $-1.31(0.03)$ & $1.19(0.02)$ & 0.98 & $-1.01(0.05)$ & $0.94(0.04)$ & 0.93 \\
\hline $\mathrm{L}_{2 \mathrm{a}}$ & $-0.53(0.14)$ & $1.05(0.10)$ & 0.64 & $-0.52(0.04)$ & $1.01(0.03)$ & 0.97 \\
\hline Apodeme DW & $-7.04(0.76)$ & $3.03(0.51)$ & 0.68 & & & \\
\hline
\end{tabular}

senting correlations higher than 0.98 with $\mathrm{CW}$ and length, height and width of the chelipeds (these variables showed minimum correlations with the other axes obtained). The correlations between MAs and MRs and axis 1 were always negative and low $(-0.43<$ $\mathrm{r}<0$ ). Axis 2 differentiated individuals of Liocarcinus arcuatus and $L$. depurator, which were associated with high MAs and MRs respectively, whereas the scores of individuals of Necora puber with this axis were small. Axis 3 had a positive correlation with both MAs and
MRs, and set $N$. puber, which had positive scores, in opposition to the 2 species of Liocarcinus. Together, axes 2 and 3 defined the biomechanical variability among the portunid species analyzed, which may be interpreted as a gradient presenting $L$. depurator on one end (having chelipeds with a high MR and great mobility, low MAs! and L. arcuatus on the other end (which has less mobile chelae with a low MR). $N$. puber presented intermediate biomechanical characteristics. 
Table 5. Results of ANCOVA carried out to compare the parameters of the allometric equations (slope $b$ and intercept $\log a$ ) that relate carapace width and the different variables obtained to determine the mechanical advantages and dry weight (DW) of the muscle, tegument and apodeme of the propodius of both chelipeds between sexes for each species. F-statistic and significance level are shown ( $\left.p<0.05, \cdots p<0.01,{ }^{n s} p>0.05\right)$. Intercepts were compared only when slopes were not significantly different $(p>0.05)$

\begin{tabular}{|c|c|c|c|c|c|c|}
\hline \multirow[b]{2}{*}{ Crusher cheliped } & \multicolumn{2}{|c|}{$\begin{array}{c}\text { Necora } \\
\text { puber } \\
\text { Slope Intercept }\end{array}$} & \multicolumn{2}{|c|}{$\begin{array}{l}\text { Llocarcinus } \\
\text { depurator } \\
\text { Slope Intercept }\end{array}$} & \multicolumn{2}{|c|}{$\begin{array}{c}\text { Liocarcinus } \\
\text { arcuatus } \\
\text { Slope Intercept }\end{array}$} \\
\hline & & & & & & \\
\hline Muscle DW & $6.04^{\circ}$ & - & $1.81^{\mathrm{ns}}$ & $0.55^{\mathrm{ns}}$ & $32.18^{*}$ & - \\
\hline Tegument DW & $12.97^{\cdots}$ & - & $0.23^{116}$ & $0.22^{\mathrm{nk}}$ & $62.18^{\circ}$ & - \\
\hline $\mathrm{L}_{1}$ & $18.39 \cdots$ & - & $3.26^{\mathrm{ns}}$ & $2.67^{\mathrm{ns}}$ & $159.59^{\circ}$ & - \\
\hline $\mathrm{L}_{2 \mathrm{a}}$ & $7.58^{*}$ & - & $15.36 \cdots$ & - & $153.98^{\circ}$ & - \\
\hline $\mathrm{L}_{2 b}$ & $18.29^{\circ}$ & - & $6.98 \cdots$ & - & $81.45^{\circ}$ & - \\
\hline Apodeme DW & $0.30^{n s}$ & $0.29^{\mathrm{ns}}$ & $0.46^{\mathrm{ns}}$ & $0.32^{\text {ns }}$ & $17.90^{\circ}$ & \\
\hline Pincer cheliped & & & & & & \\
\hline Muscle DW & $1.92^{\mathrm{ns}}$ & $1.80^{\mathrm{ns}}$ & $0.52^{\mathrm{ns}}$ & $0.00^{\mathrm{ns}}$ & $17.81^{\circ}$ & - \\
\hline Tegument DW & $1.98^{\mathrm{ns}}$ & $1.09^{n s}$ & $2.21^{\mathrm{me}}$ & $0.67^{\mathrm{nc}}$ & $15.82^{\circ}$ & - \\
\hline $\mathrm{L}_{1}$ & $10.83 \cdots$ & - & $5.00^{\circ}$ & - & $80.01^{\prime}$ & - \\
\hline $\mathrm{L}_{2 \mathrm{~d}}$ & $2.59^{\mathrm{ns}}$ & $2.36^{\text {ns }}$ & $8.98^{*}$ & - & $8.02^{\circ}$ & - \\
\hline Apodeme DW & $1.79^{\mathrm{ns}}$ & $0.20^{\mathrm{ns}}$ & $3.90^{\text {ns }}$ & $0.78^{\mathrm{ns}}$ & & \\
\hline
\end{tabular}

\section{Diet composition}

Gut-contents analysis indicated that portunid crabs in the Ría de Arousa have generalist diets, preying mainly on macroinvertebrates (crustaceans, molluscs and echinoderms) which are sessile or have little mobility; only in the case of Liocarcinus arcuatus did seaweeds have a high importance in the food composition (Table 7, see also Freire 1993, in press, Freire \& González-Gurriarán 1995). Interspecific and spatial differences determine most of the trophic diversity among these decapods, and ontogenetic changes are responsible for most of the intraspecific trophic variability. Taking the mobility and morphology (presence and type of exoskeleton) of the prey into account, the diet composition in the different habitats was sim-

Table 6. Results of ANCOVA carried out to compare the parameters of the allometric equations (slope $b$ and intercept loga) relating carapace width and the different variables obtained in order to determine the mechanical advantages and the dry weight (DW) of the muscle, tegument and apodeme of the chelipeds between species for each sex. F-statistic and significance level are shown $(" p<0.05, \cdots p<0.01)$. In cases where significant differences existed $(p<0.05)$, pairwise a posteri comparisons were made using the Bonferroni correction to maintain a probability level of $p=0.05$ (underlined species were not significantly different) NPU: Necora puber. LDE: Liocarcinus depurator, LAR: L. arcuatus

\begin{tabular}{|c|c|c|c|c|c|c|c|c|}
\hline & \multicolumn{4}{|c|}{ Slope } & \multicolumn{4}{|c|}{ Intercept } \\
\hline \multicolumn{9}{|l|}{ Males } \\
\hline \multicolumn{9}{|l|}{ Crusher cheliped } \\
\hline Muscle DW & $31.88^{\cdots}$ & NPU & LAR & LDE & & & & \\
\hline Tegument DW & $264.06^{*}$ & NPU & LDE & LAR & & & & \\
\hline $\mathrm{L}_{1}$ & $126.39^{* *}$ & $\underline{L D E}$ & $\mathrm{NPU}$ & LAR & NPU & LDE & & \\
\hline $\mathrm{L}_{2 a}$ & $92.42 *$ & NPU & $\mathrm{LDE}$ & LAR & & & & \\
\hline $\mathrm{L}_{2 \mathrm{~b}}$ & $97.71 \cdots$ & NPU & LDE & LAR & NPU & LDE & & \\
\hline Apodeme DW & $34.06^{\cdots}$ & LAR & LDE & NPU & & & & \\
\hline \multicolumn{9}{|l|}{ Pincer cheliped } \\
\hline Muscle DW & $18.74^{\cdots}$ & NPU & LAR & LDE & LAR & NPU & & \\
\hline Tegument DW & $125.49 \cdots$ & $\mathrm{NPU}$ & LDE & LAR & & & & \\
\hline $\mathrm{L}_{1}$ & $111.97^{\cdots}$ & NPU & LDE & LAR & $\mathrm{LDE}$ & NPU & & \\
\hline $\mathrm{L}_{2 \mathrm{a}}$ & $7.17 \cdots$ & NPU & LAR & LDE & LAR & NPU & & \\
\hline Apodeme DW & $19.88^{\prime \prime}$ & NPU & LDE & LAR & LAR & LDE & & \\
\hline \multicolumn{9}{|l|}{ Females } \\
\hline \multicolumn{9}{|l|}{ Crusher cheliped } \\
\hline Muscle DW & $13.32^{\bullet}$ & LAR & NPU & LDE & NPU & LAR & & \\
\hline Tegument DW & $23.28 \cdots$ & NPU & $\mathrm{LAR}$ & $\underline{\mathrm{L} D E}$ & LDE & LAR & & \\
\hline $\mathrm{L}_{1}$ & $8.46^{\prime}$ & $\underline{\mathrm{LAR}}$ & LDE & NPU & NPU & LDE & LAR & \\
\hline $\mathrm{L}_{2 \dot{d}}$ & $12.28^{\circ}$ & LDE & LAR & NPU & LAR & LDE & $\mathrm{NPU}$ & LAR \\
\hline $\mathrm{L}_{2 \mathrm{~b}}$ & $19.97^{\cdots}$ & $\mathrm{LAR}$ & $\overline{N P U}$ & $\overline{\mathrm{LDE}}$ & NPU & LDE & & \\
\hline Apodeme DW & $17.68^{\cdots}$ & $\mathrm{NPU}$ & $\mathrm{LDE}$ & & & & & \\
\hline \multicolumn{9}{|l|}{ Pincer cheliped } \\
\hline Muscle DW & $11.85^{\cdots}$ & LAR & NPU & $\underline{\mathrm{LDE}}$ & NPU & $\underline{L A R}$ & $\underline{\mathrm{LDE}}$ & NPU \\
\hline Tegument DW & $26.68^{\cdots}$ & NPU & $\mathrm{LDE}$ & $\overline{\mathrm{LAR}}$ & $\mathrm{LDE}$ & $\overline{N P U}$ & & \\
\hline $\mathrm{L}_{1}$ & $3.23^{\circ}$ & LDE & LAR & $\underline{N P U}$ & NPU & LAR & LDE & \\
\hline $\mathrm{L}_{2 \mathrm{a}}$ & $5.31 \cdots$ & LAR & NPU & $\overline{\mathrm{LDE}}$ & NPU & $\mathrm{LDE}$ & $\mathrm{LAR}$ & \\
\hline Apodeme DW & $4.58^{\circ}$ & $\underline{\operatorname{LDE}}$ & NPU & & NPU & LDE & & \\
\hline
\end{tabular}


Fig. 2. Interspecific principal component analysis carried out for each sex. Ordination of the morphometric and biomechanical variables and centroids of the scores for each species on the axes 1,2 and 3 (the identification of length, width and height because they are distributed very closely to carapace width, CW). The percentage of variance explained by each axis is shown in parenthesis. $\mathrm{MA}_{\mathrm{ra}}, \mathrm{MA}_{\mathrm{b}}$ : mechanical advantages of the right chelipedi $\mathrm{MA}_{\mid \vec{a}}$ : mechanical adavantage of the left cheliped; $M R_{r}, M R_{l}$ : muscle ratio of the right and left chelipeds respectively of both chelipeds is omitted
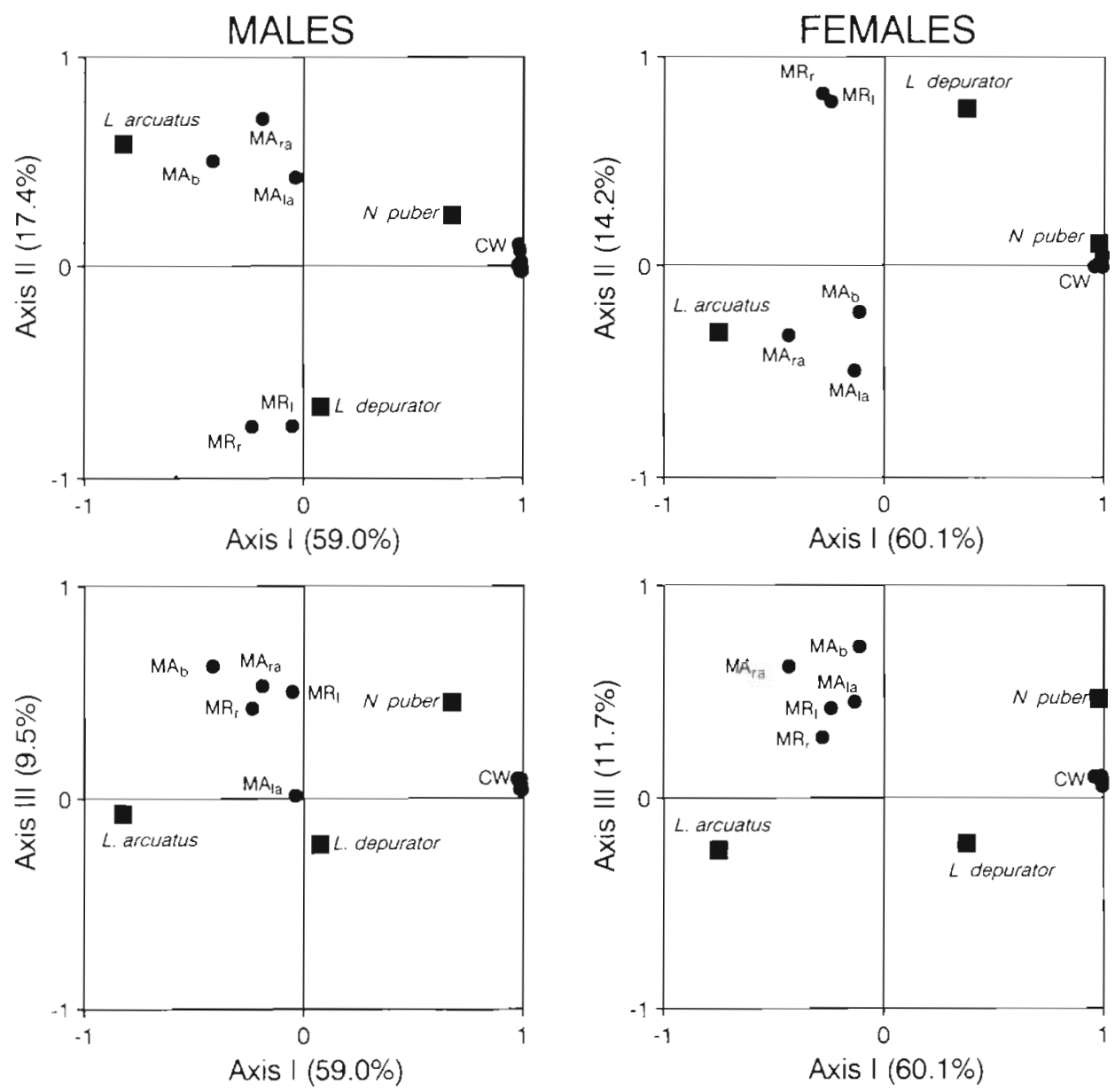

DISCUSSION

ilar for each species (Table 7, Fig. 3). Between-habitat differences appeared in the raft zones and areas not devoted to mussel culture and corresponded with differences in the epifaunal and infaunal prey communities (Freire 1993, in press, Freire \& GonzálezGurriarán 1995). Thus, L depurator increased its consumption of slow-moving prey without an exoskeleton (mainly polychaetes) in the central channel and reduced its predation on mobile prey with exoskeletons. In the case of L. arcuatus, soft-bodied prey, both mobile and sessile, were more important on the beach than in the raft area. The prey consumed by L. depurator presented high morphological diversity, as all the types of food items mentioned above make up an important part of its diet. L. depurator showed an ontogenetic increase in the consumption of prey having hard exoskeletons (Fig. 4). In the early life stages, between 10 and $30 \mathrm{~mm} \mathrm{CW}$, mobile prey increased their importance in the diet, while crabs with $\mathrm{CW}$ $>30 \mathrm{~mm}$ preyed more on sessile organisms. In Necora pübel and $L$. dicuaius there was iittie ontogenetıc varlability in the diet composition when considering prey morphology and mobility.
The morphology and biomechanical characteristics of chelipeds may determine, at least in part, predation techniques and prey selection mechanisms of decapod crustaceans. The findings of this morphometric analysis show that although the size of the chelipeds relative to body size is similar in Necora puber, Liocarcinus depurator and Liocarcinus arcuatus, the biomechanical parameters vary greatly. In this sense both sexes show an interspecific morphometric gradient with an inverse relationship between mechanical advantages (MAs) and muscle mass ratio (MR) of the chelipeds.

The functional structure of the chelipeds of Liocarcinus depurator, the species with the highest morphological diversity of prey, is more versatile. MAs are relatively low, giving the chelipeds greater mobility, and the decrease in force produced is probably compensated for by an increase in muscle mass. L. arcuatus, on the other hand, has a lower MR, for which reason the torce produced depends more on the design of the chelipeds, with MAs higher than those of the other species studied. These characteristics give rise to appendages 


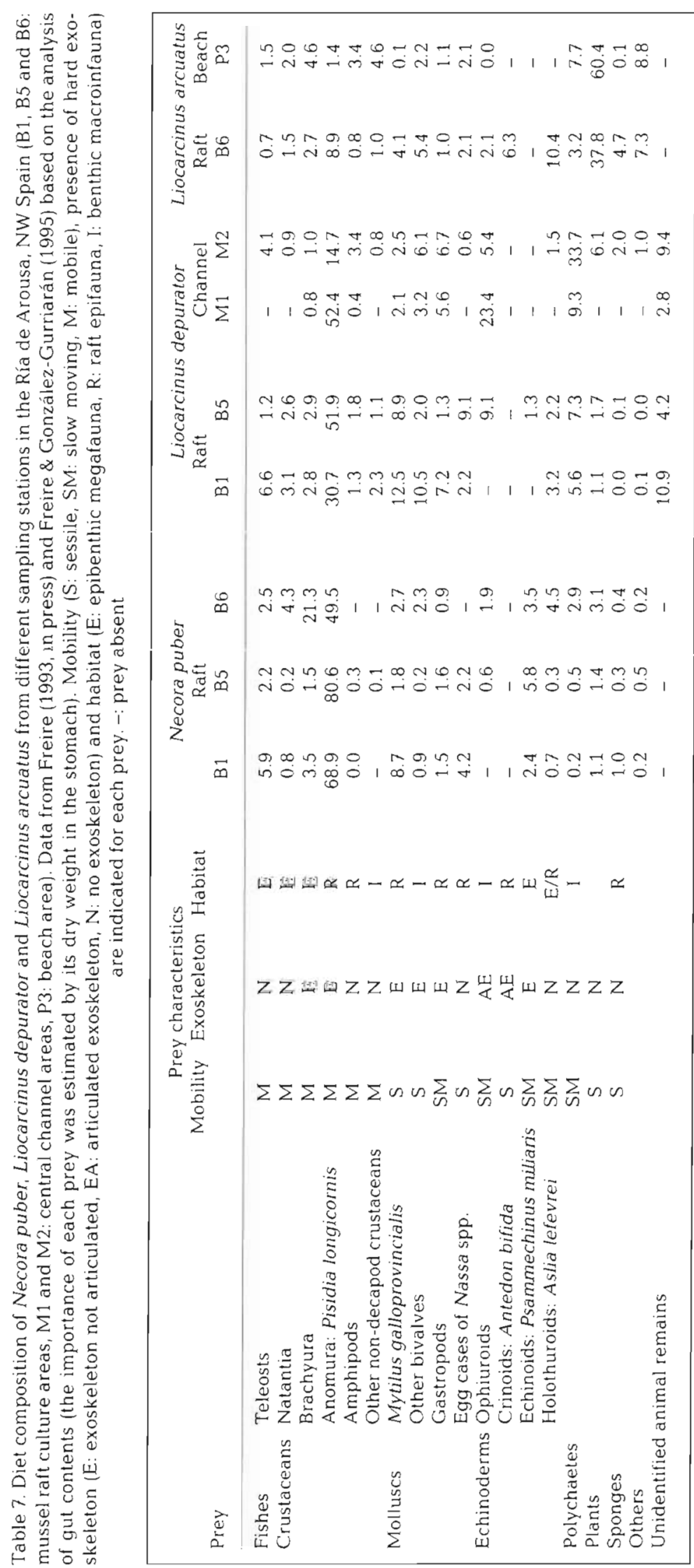

that are relatively immobile, which is reflected in a diet made up chiefly of sedentary soft-bodied prey. Necora puber has intermediate trophic and biomechanical characteristics; its prey are primarily mobile, and organisms with hard exoskeletons are dominant both in the mobile and the sessile or slow-moving prey groups.

Ontogenetic changes in the diet are related to the absolute growth of the chelipeds and partially determined by biomechanical factors. Brown el al. (1979) reported an increase in the absolute force produced as body size increases in decapods, independent of the morphological differences between species. Liocarcinus depurator shows a negative correlation between the MAs of the chelipeds and carapace width $(\mathrm{CW})$, while the $M R$ remains constant, causing a negative allometry in the force produced and an increase in the mobility of the appendages throughout growth. In spite of these changes in relative growth, there is an absolute increase in muscle mass and cheliped size, which causes an increase in the consumption of prey with hard exoskeletons. Our results suggest that the ontogenetic changes in the diet are linked to the absolute growth of the chelipeds, giving access to the more resistant prey, whereas Abello et al. (1990) showed that the changes in relative growth are associated with sexual maturity and reproductive behaviour. In Necora puber and L. arcuatus, which did not show important diet changes with growth, the correlations between MAs and body size are generally low; however, the latter undergoes a sharp drop in the MR with growth due to a strong positive allometry in cheliped size (and tegument weight). The ontogenetic morphometrical variability of the chelipeds is related to the onset of the sexual maturity in both species (González-Gurriarán \& Freire 1994, unpubl. data), and it does not have a direct influence on feeding. Sexual variability in the diet is minimal for the 3 species (Freire 1993, in press, Freire \& GonzálezGurriarán 1995); this is related to the lack of significant differences in MAs and MRs between males and females, although cheliped size differs slightly.

It has been suggested that the evolution of the morphometric and functional diversity of the chelipeds in decapods (Schäfer 1954) is an adaptive response to the diversity of the prey communities characteristic of the habi- 

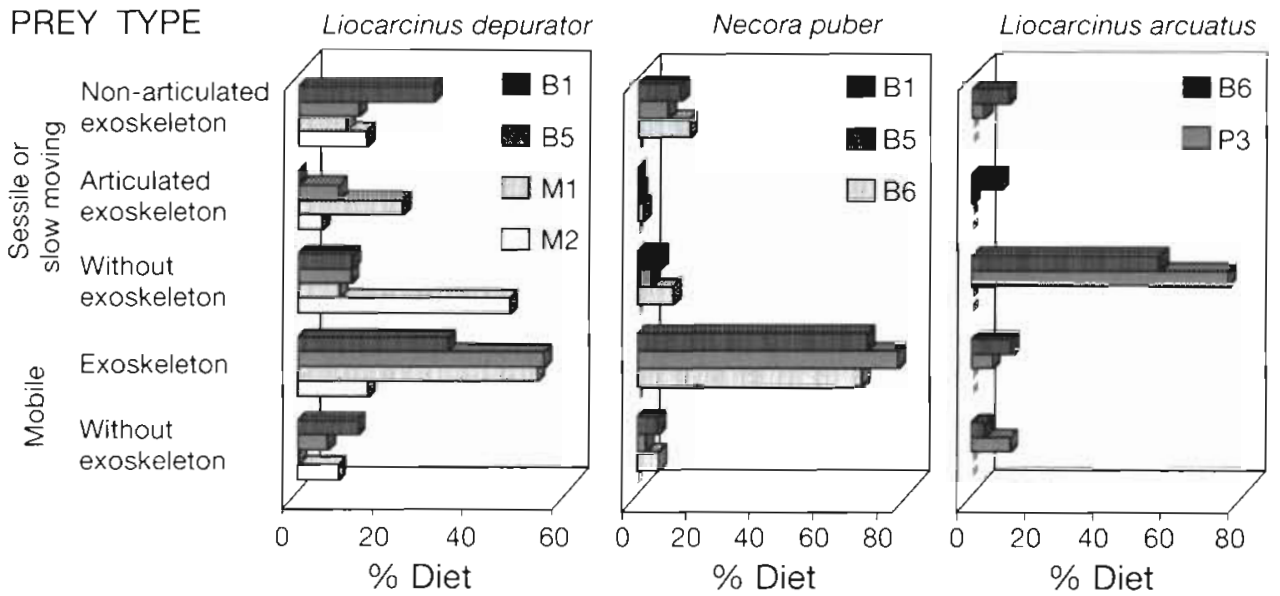

Fig. 3. Diet composition of Necora puber, Liocarcinus depurator and Liocarcinus arcuatus in terms of mobility and morphological characteristics (presence and type of exoskeleton) of the prey consumed in different sampling stations in the Ría de Arousa, NW Spain (B1, B5 and B6: mussel raft culture areas; M1 and M2: central channel areas; P3: beach area). The importance of each prey type was estimated by its dry weight in the gut contents analyzed

tats occupied by these species (Vermeij 1977, Zipser \& Vermeij 1978, Lawton \& Elner 1984). Morphological and morphometric diversity observed in different groups of decapods is due to the evolution of reproductive behaviour and intra- and interspecific agonistic interactions (Orensanz \& Galluci 1988, Kaiser et al. 1990, Lee \& Seed 1992): these processes generate chelipeds with different biomechanical characteristics, which secondarily modifies prey selection and ultimately diet composition (Kaiser et al. 1990, Lee \& Seed 1992), although probably the behavioural, physiological and habitat changes associated with sexual maturity have a stronger effect on the diet. Several authors have proven the existence of physiological adaptations in cheliped muscles related to mating (Govind et al. 1992), social hierarchy (Govind \& Pearce 1993) or feeding (Warner \& Jones 1976, Smith \& Palmer 1994).

ap Rheinallt \& Hughes (1985) and ap Rheinallt (1986) described the mechanical factors and predation techniques used by Necora puber to select different prey types and sizes. The morphology of the chelipeds in $N$. puber have a design which is more appropriate for predation on mobile prey such as crustaceans than on sessile prey such as molluscs (ap Rheinallt \& Hughes 1985). These experimental predictions are corroborated by our findings (Freire \& González-Gurriarán 1995), which show a diet dominated by the anomuran decapod Pisidia longicornis, while molluscs are a sec-

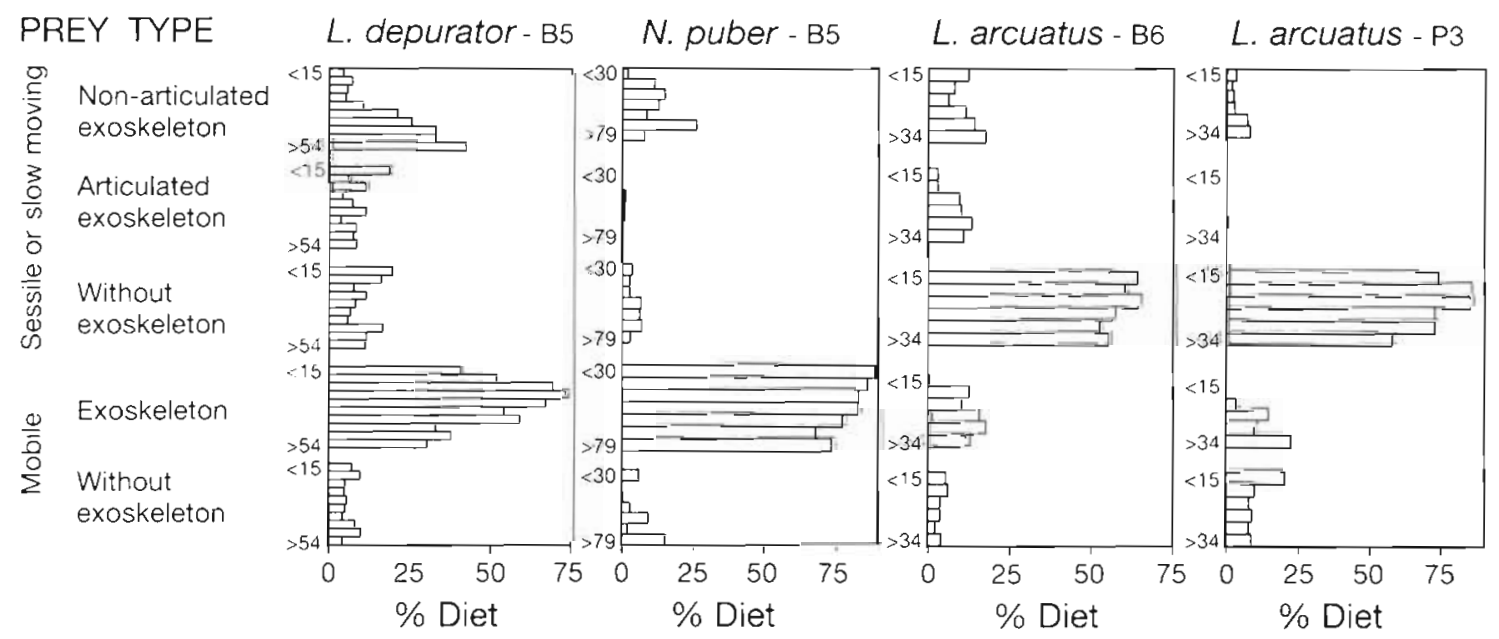

Fig. 4. Ontogenetic changes in diet composition of Necora puber, Liocarcinus depurator and Liocarcinus arcuatus in different sampling stations in the Ría de Arousa (B1 and B6: mussel raft culture areas: P3. beach area) in terms of mobility and morphological characteristics (presence and type of exoskeleton) of the prey consumed. For each species and group of prey only the first and last body size classes (carapace width) are shown (range of size classes: $5 \mathrm{~mm}$ for L. depurator and L. arcuatus, $10 \mathrm{~mm}$ for $N$. puber). The importance of each prey type was estimated by its dry weight in the gut contents analyzed 
ondary component. On the other hand, both the mussel and other bivalves and gastropods are of relatively more importance in the diet of Liocarcinus depurator and $L$. arcuatus in the same areas of the Ría de Arousa (Table 7. Freire 1993, in press). In relation to prey size selection, in the Ría de Arousa, a positive correlation between the size of the predator and its crustacean prey (especially in the case of specimens of $P$. longicornis consumed by $L$. depurator and $N$. puber) which agrees with the experimental predictions has been observed (Freire 1993).

In conclusion, the comparative morphological analysis carried out on the 3 species of portunids points to the existence of an interspecific variability that is largely associated with differences in the morphology and mobility of the prey consumed. Secondly, on an intraspecific level, the sexual and ontogenetic variability is lower and appears to be linked to the onset of sexual maturity and reproductive behaviour Within a species, the morphometric and biomechanical changes observed may be attributed to non-trophic selection processes (Hartnoll 1974, 1978, Orensanz \& Galluci 1988 ), and they have no major influence on the diet, which is conditioned mainly by the absolute growth of the chelipeds and muscle mass (Brown et al. 1979). On a longer evolutionary scale, the interspecific diversity in feeding habits and morphometry are correlated (Lawton \& Elner 1984), although the causal mechanism could not be determined due to a lack of sufficient information on mating systems and social interactions in these species.

Acknowledgements. This research was funded by the Conselleria de Pesca, Marisqueo e Acuicultura of the Xunta de Galicia through FEUGA. J.F held a fellowship from the Ministerio de Educación y Ciencia (Plan de Formación de Personal Investigador) during the course of this study. M. J. Kaiser and one anonymous referee improved the manuscript with their criticisms. C. P. Teed assisted in the preparation of the English version of the manuscript.

\section{LITERATURE CITED}

A.belló P, Pertierra JP, Gili JM (1990) Sexual size dimorphism, relative growth and handedness in Liocarcinus depurator and Macropipus tuberculatus (Brachyura: Portunidae). Sci Mar 54:195-202

ap Rheinallt $T$ (1986) Size selection by the crab Liocarcinus puber feeding on mussels Mytilus edulis and on shore crabs Carcinus maenas: the importance of mechanucal factors. Mar Ecol Prog Ser 29:45-53

ap Rheinallt T, Hughes RN (1985) Handling methods used by the velvet swimming crab Liocarcinus puber when feeding on molluscs and shore crabs. Mar Ecol Prog Ser 25 $63-70$

Blundon JA, Kennedy VS (1982) Mechanical and behavioral aspects of blue crab, Callinectes sapidus (Rathbun), predation on Chesapeake Bay bivalves. J Exp Mar Biol Ecol $65: 47-65$
Brown SC, Cassuto SR, Loos RW (1979) Biomechanics of chelipeds in some decapod crustaceans. J Zool Lond 188: $143-159$

Elner RW (1980) The influence of temperature, sex and chela size in the foraging strategy of the shore crab. Carcinus maenas (L.). Mar Behav Physiol 7:15-24

Fernández L, González-Gurriarán E, Freire J (1991) Population biology of Liocarcinus depurator (Brachyura: Portunidae) in mussel raft culture areas in the Ría de Arousa (Galicia, NW Spain). J Mar Biol Ass UK 71:375-390

Freire J (1993) Alimentación de los crustáceos decápodos (Brachyura) en la Ría de Arousa: influencia del cultivo de mejillón. PhD thesis, Universidade da Coruña

Freire J (in press) Feeding ecology of Liocarcinus depurator (Decapoda: Portunidae) in the Ría de Arousa (Galicia, NW Spain): effects of habitat, season and life history. Mar Biol

Freire J, Fernández L, González-Gurriarán E (1990) Influence of mussel raft culture on the diet of Liocarcinus arcuatus (Leach) (Brachyura: Portunidae) in the Ría de Arousa (Galicia, NW Spain). J Shell Res 9:45-57

Freire J, González-Gurriarán E (1995) Feeding ecology of the velvet swimming crab Necora puber (Crustacea, Decapoda) in mussel raft culture areas of the Ría de Arousa (Galicia, NW Spain). Mar Ecol Prog Ser 119:139-154

Freire J, Muiño R, Fernández L, González-Gurriarán E (1991) Life cycle of Liocarcinus arcuatus (Brachyura: Portunidae) in the Ría de Arousa (Galicia, NW Spain): role of beach and mussel raft culture areas. PSZN I Mar Ecol 12: $193-210$

González-Gurriarán E (1982) Estudio de la comunidad de crustáceos decápodos (Brachyura) en la Ría de Arousa (Galicia-NW Espana), y su relación con el cultivo de mejillón en batea. Bol Inst Esp Oceanogr 7:223-25

González-Gurriarán E (1985) Crecimiento de la nécora Macropipus puber (L.) (Decapoda, Brachyura) en la Ría de Arousa (Galicia, NW España), y primeros datos sobre la dinámica de la población. Bol Inst Esp Oceanogr 2:33-51

González-Gurriarán E, Freire J (1994) Sexual maturity in the velvet swimming crab Necora puber (Brachyura: Portunidae): morphometric and reproductive analyses. ICES J Mar Sci 51:133-145

González-Gurriarán E, Freire J, Fernández L, Poza E (1989) Incidencia del cultivo de mejillón en la dieta de Liocarcinus depurator (L.) (Brachyura: Portunidae) en la Ría de Arousa (Galicia, NW España). Cah Biol Mar 30:307-31

Govind CK, Pearce J (1993) Simılarity in claw muscles among the three male morphs of the fresh-water prawn Macrobrachium rosenbergii. J Crust Biol 13:138-141

Govind CK, Read AT, Claxton WT, Elner RW (1992) Neuromuscular analysis of the chela-closer muscle associated with precopulatory clasping in male snow crabs, Chionoecetes opilio. Can J Zool 70:2356-2363

Hartnoll RG (1974) Variation in growth pattern between some secondary sexual characters in crabs (Decapoda Brachyura). Crustaceana 27:131-136

Hartnoll RG (1978) The determination of relative growth in Crustacea. Crustaceana 34:281-293

Hughes RN, Seed R (1981) Size selection of mussels by the blue crab Callinectes sapidus: energy maximizer or time minimizer? Mar Ecol Prog Ser 6:83-89

Kaiser MJ, Hughes RN, Reid DG (1990) Chelal morphometry, prey-size selection and aggressive competition in green and red forms of Carcinus maenas. J Exp Mar Biol Ecol 1.40:121-134

Lawton P, Elner RW (1984) Feeding in relation to morphometrics within the genus Cancer evolutionary and ecological considerations. In: Melteff BR (ed) Proceedings of 
the Symposium on Dungeness Crab Biology and Management 9-11 Oct 1984, Anchorage, Alaska, USA. Alaska Sea Grant College Program, Fairbanks, p 357-379

Lee SY, Seed R (1992) Ecological implications of cheliped size in crabs: some data from Carcinus maenas and Liocarcirus holsatus. Mar Ecol Prog Ser 84:151-160

Orensanz JM, Gallucci VF (1988) Comparative study of postlarval life-history schedules in four sympatric species of Cancer (Decapoda:Brachyura:Cancridae). J Crust Biol 8: $187-220$

Romero P, González-Gurriarản E, Penas E (1982) Influence of mussel rafts on spatial and seasonal abundance of crabs in the Ria de Arousa, North-West Spain. Mar Bıol 72:201-210

Schäfer W (1954) Form und Funktion der Brachyuren-Schere. Abh Senckenb NatForsch Ges 489:1-65

This article was presented by R. Hughes (Senior Editoria! Advisor), Bangor, UK
Smith LD, Palmer AR (1994) Effects of manipulated diet on size and performance of brachyuran crab claws. Science 264:710-712

Tenore KR, Boyer LF, Cal RM, Corral J, García-Fernández C, González N, González-Gurriarán E, Hanson RB, Iglesias J, Krom M, López-Jamar E, McClain J, Pamatmat MM, Pérez A, Rhoads DC, Santiago G. Tietjen J, Westrich J, Windom HL (1982) Coastal upwelling in the Rías Bajas, NW Spain: contrasting the benthic regimes of the Rias de Arousa and de Muros. J Mar Res 40:701-772

Vermeij GJ (1977) Patterns in crab claw size: the geography of crushing. Syst Zool 26:138-151

Warner GF, Jones AR (1976) Leverage and muscle type tn crab chelde (Crustacea: Brachyura). J Zool Lond 180:57-68

Zipser E, Vermeij GJ (1978) Crushing behavior of tropical and temperate crabs. J Exp Mar Biol Ecol 31:155-172

Manuscript first received: April 1, 1995

Revised version accepted: February 2, 1996 